Management and Performance in U.S. Nursing Homes

\author{
Anna A. Amirkhanyan \\ Associate Professor \\ Department of Public Administration and Policy \\ School of Public Affairs, American University \\ Ward Circle Building, 324 \\ 4400 Massachusetts Ave, N.W. \\ Washington, DC 20016 \\ amirkhan@american.edu
}

Kenneth J. Meier

Distinguished Professor, Charles H. Gregory Chair in Liberal Arts, and Director of the Project for Equity, Representation and Governance

Department of Political Science, Texas A\&M University 4348 TAMU

College Station, TX 77843-4348

kenneth-j-meier@tamu.edu

Laurence J. O'Toole, Jr.

Golembiewski Professor of Public Administration and Distinguished Research Professor Department of Public Administration and Policy, School of Public and International Affairs 204 Baldwin Hall

The University of Georgia

Athens, Georgia 30602

cmsotool@uga.edu

Mueen A. Dakhwe

Program Coordinator, Brazos County Health Department

201 N Texas Ave, Bryan, TX 77803

dr.mueendakhwe@gmail.com

Shawn Janzen

5415 Connecticut Ave NW Unit 631, Washington, DC 20015

shawn@janzengroup.net 


\title{
Management and Performance in U.S. Nursing Homes
}

\begin{abstract}
Accountability pressures have generated complex performance measurement regimes to evaluate and improve public or publicly-funded services. Performance management, however, faces many challenges including the tradeoffs posed by numerous dimensions of performance and a lack of consensus on which organizational and environmental factors can improve these results. This study seeks to understand the effect of management and other factors on different dimensions and measures of performance in U.S. public, nonprofit, and for-profit nursing homes. Using a hybrid data set that combines archival government data on performance in nursing homes with a recent nursing home administrators' survey, we find that innovative management significantly ${ }^{1}$ improves the quality of care. In addition, more innovation and less power sharing in management are associated with serving fewer Medicaid-funded clients. Significant differences in performance exist across public, nonprofit, and for-profit organizations. These differences are notable across both the archival and perceptual models of performance.
\end{abstract}

\footnotetext{
${ }^{1}$ Throughout the paper, the term "significance" refers exclusively to "statistical significance."
} 


\section{Management and Performance in U.S. Nursing Homes \\ INTRODUCTION}

Organizational performance is an increasingly global concern for public administration scholars and practitioners (Boyne, Meier, O'Toole and Walker 2006; O'Toole and Meier 2011; Radin 2006). Across service areas, mounting accountability pressures motivate the creation of complex performance measurement systems to help evaluate and improve public or publiclyfunded services (Andrews, Boyne and Walker 2006a; Heinrich 2012; Heinrich and Marshke 2009; Selden and Sowa 2004). Among the challenges to the use of performance data are tradeoffs posed by numerous dimensions of performance and a lack of consensus on which managerial, organizational, and environmental factors can improve these results. Related to these challenges, rigorous empirical research that identifies such factors is limited. The current article contributes to our discipline's quest for administrative means to achieve public goals. We seek to understand the effect of management and other organizational and environmental factors on numerous dimensions and measures of performance in public, nonprofit, and for-profit organizations - with U.S. nursing homes as the empirical settings. An increasingly salient public policy area in the U.S. due to the growth of elderly population, this field is a good example of a policy-specific performance measurement system, with its intergovernmental and cross-sector relationships, unique complexities, biases, and perverse incentives.

This article makes several contributions to public management and health policy literature. First, we focus on three broad areas of organizational management - innovation, sharing power, and external management. Our findings suggest a significant and positive association between innovation management and service quality. Innovation and power sharing are also significantly related to greater access to care. Notably, after including management in 
the analysis, public, nonprofit, and for-profit ownership remains a key factor in explaining the variation in nursing home quality and access. Second, our study focuses on two dimensions of performance - service quality and access for low-income clients - using both the archival indicators and the perceptual managerial assessments. Our findings show marked differences in the managerial correlates of these dimensions and measures of performance. For this analysis, we use a hybrid ${ }^{2}$ data set that combines government data on nursing home performance from the Centers for Medicare and Medicaid Services (CMS) with a nursing home administrators' survey of internal management strategies. Third, this study contributes to the health policy and health care administration literature. We find that innovation management, but not power sharing or external management, is associated with service quality in a health care market with fairly low service measurability, ${ }^{3}$ technological sophistication, dependent clientele, and extensive thirdparty financing and regulation. Our results may be more generalizable to other health and human services, as well as to the fields of long-term care in other developed nations, where higher employment rates, job-related mobility, substantial retirement benefits, and prevalence of nuclear families create demand for institutional long-term care.

\section{LITERATURE REVIEW}

Because this study examines both the measurement of organizational performance and the factors associated with it, several research literatures are relevant. They include organization theory, public management, and health policy.

\footnotetext{
${ }^{2}$ For the purposes elaborated below, hybrid data are considered particularly useful in the public management literature (Boyne et al. 2006).

${ }^{3}$ The effect of management and other factors may differ in the context of higher service measurability, i.e., with more observable, verifiable, and quantifiable outcomes. Similar to other human services, long term care clients' improvement can be hard to measure. It is also hard to connect client outcomes to the care interventions that typically involve high levels of professional discretion. Despite this, quality assessment of US nursing homes is fairly elaborate, capturing inputs, processes, outputs, and outcomes with an extensive list of CMS measures.
} 
Organizational Performance and the Sources of Data. Defined broadly as "the character and consequences of service provision by public agencies," public sector performance is a socially constructed and multi-dimensional phenomenon (Brewer and Selden 2000; Forbes, Hill and Lynn 2006, 255). Understanding the sources of performance improvements, including management, is a gargantuan task for a number of reasons (Boyne 2002; Lynn, Heinrich and Hill 2000). Government agencies often have conflicting values and objectives, and their attainment involves making tradeoffs (Brewer 2006; Weiss, Bloom, and Brock 2014). Also, many stakeholders are involved in the collection and use of performance data, making it difficult to develop a coherent picture of performance improvement (Andrews, Boyne and Walker 2006b; Radin 2006). Finally, performance management goes beyond the "rational" analyses, and involves political, cultural, and other considerations (Eggleston and Zeckhauser 2002).

The many objectives of government agencies are reflected in a range of dimensions of performance related to organizational inputs and processes (e.g., management, structures, resources, efficiency, or fairness), outputs (e.g., quality or timeliness), and outcomes (e.g., client or community impacts) (Addicott and Ferlie 2006; Boyne 2002; Forbes et al., 255).

Understanding and accounting for this complexity requires innovative theory-building and rigorous research methodology - both applied to a rich set of relevant data. Furthermore, when the reality is complex, the measurement can hardly be simple. Measures that lack validity and reliability are of little use to practitioners (Meier and O'Toole 2013a). The literature highlights an important distinction between archival and perceptual measures of performance. Reflecting the managers', staff, or clients' views on services, perceptual measures allow comparability of data across services or jurisdictions. Client surveys, in particular, are considered valid and relevant for public management (Shingler, Van Loon, Alter and Bridger 2008; Van Ryzin, 
Immerwahr and Altman 2008). Perceptual measures can be problematic: they often include nonrandom measurement error and are prone to positivity bias (Boyne et al. 2006). ${ }^{4}$ Perceptual measures can also entail common source bias, when systematic error variance is shared among several variables from the same source (Meier and O'Toole 2013a). ${ }^{5}$ Data from archival sources are developed by professionals in a standard fashion to minimize discretion and organizational biases. Archival measures may fail to capture all organizational outcomes, ${ }^{6}$ and may result in dysfunctions - cheating, creaming, or goal displacement. Nonetheless, archival measures are widely regarded as the "gold standard" of performance measurement, ranging from standardized tests, to agency-wide scores and societal indicators ${ }^{7}$ (O’Mahony and Stevens 2006). Empirical studies across fields suggest that perceptual and archival measures of quality, quantity, or equity are not strongly correlated (Andrews, Boyne and Walker 2006b; Bommer et al. 1995; Brown and Coulter 1983; Kelly and Swindell 2002; Meier and O'Toole 2013b; Van Ryzin et al. 2008). ${ }^{8}$ Examinations of the effect of various factors on both the perceptual and archival measures are scarce, and the findings are mixed (Amirkhanyan, Kim and Lambright 2014; Shingler et al. 2008). Our analysis relies on archival measures of performance reflecting the nursing homes' compliance with federal regulations of the quality of life, care, administration, and physical environment; as well as access to care for Medicaid-funded clients. The goal of this study is to investigate how performance is related to management, and various organizational and environmental factors (such as ownership, size, staffing, or competition). We supplement our

\footnotetext{
${ }^{4}$ Meier and O'Toole (2013a) find that managers tend to report favorably on their practices and organizational successes, even after accounting for task difficulty or resource constraints.

${ }^{5}$ Thus, relationships between variables can be inflated or deflated (Meier and O'Toole 2013b). Although there are better and worse ways of addressing this issue (Favero and Bullock 2015), no method is perfect. Perceptual measures work better if they involve narrowly defined dimensions of performance (Meier and O'Toole 2013b).

${ }^{6}$ Archival data may reflect judgments of powerful stakeholders on elements of performance.

${ }^{7}$ These include, but are not limited to, life expectancy, disease rates, or literacy.

${ }^{8}$ Meier and O'Toole (2013b) find correlation coefficient typically ranges between 0.2 and 0.6 . Since the shared variance is the square of the correlation, this suggests rather sizable differences between the two types of measures.
} 
analysis with the administrators' perceptual assessments of their facilities, to contribute to the literature on the antecedents of perceptual and archival performance data. ${ }^{9}$

Management and Organizational Performance. Public managers and policy makers can rarely improve outcomes directly. Instead, they manipulate the antecedents even if there is little conclusive research on the determinants of performance (Boyne 2003; Forbes et al. 2006, 255). The sources of performance improvement are numerous: financial and human resources, organizational structure (e.g., centralization, size, and formalization), ownership, support by external stakeholders, market conditions, culture, client traits, and many others (Amirkhanyan, Kim and Lambright 2008; Boyne and Meier 2009; Brewer and Selden 2000; Lynn et al. 2000; Pandey and Moynihan 2006). Accounting for these factors in a given field is crucial in understanding the main drivers of service improvements.

Of the many internal and external factors, organizational management has emerged as an important point of leverage (Boyne, et al. 2006). Studies confirm that management capacities and practices positively influence dimensions of organizational performance in the fields of human services, public education, and law enforcement (Andrews et al. 2006a; Boyne 2003; Brewer 2006; Moynihan 2008; Moynihan and Pandey 2005; Nicholson-Crotty and O’Toole 2004; O’Toole and Meier 2011; Selden and Sowa 2004). In public administration, the questions of how to conceptualize management and what its impacts are on performance are fundamentally important (Forbes et al. 2006, 255; Lynn et al. 2000). Managers pursue an almost limitless plethora of specific activities: framing the goals, setting up internal and external structures and levels of supervision, motivating/incentivizing the participants, shaping cultures, building partnerships, complying with mandates, or adopting best practices of the field (Forbes et al.

\footnotetext{
${ }^{9}$ This will provide important evidence on the propensity of subjective measures to suppress or falsely identify relationships with variables commonly included in organizational performance models.
} 
2006: 255; Kenis 2006; Lynn et al. 2000; Rainey and Steinbauer 1999). While it is difficult to account for all of these distinct, micro-level activities, many of which are specific to the service context, some scholars focus on the broader, overarching areas of management.

We focus on three such broad areas. The first and second areas of management refer to the internal and external focus of managerial activities, respectively. Thus, managers work within organizations; and in managing staff and organizational processes, their approach to organizational governance can vary from power sharing to more centralized control. Externally, managers handle the environment and its influences on organizations. The third broader area is innovation management. Reflecting the managers' propensity to facilitate organizational change and learning by exploring new ideas and practices, it bridges the internal and external organizational settings. These three areas are central to the health care and nursing home care context, as the literature review suggests. Below, we elaborate on the how these three broader areas of management are related to organizational performance.

First, numerous influential theory-building studies in public management have focused on the extent of shared power while managing within organizations. Moynihan and Pandey (2005) find that centralization and limited staff autonomy stifle the efforts to make positive changes, while shared decision-making can improve performance. Brewer and Selden (2000) stress the importance of task structure - flexible management allowing the employees to make work-related decisions - in improving program outcomes. According to Boyne (2003), softer management styles, with attention to the employees' aspirations, rather than manipulation and control, may be a key source of program improvement. Additional literature explores overlapping and still evolving concepts of shared, democratic, participatory, or devolved management styles (Gronn 2008; Harris 2008). Participatory management reflects shared 
decision-making beyond the distribution of positional power. It improves the employees' job satisfaction and sense of ownership; it also promotes efficiency, innovation, and knowledgesharing, and reduces ambiguity and conflict (Dearden, Carter, David, Kowalski and Surridge 1999; Kim 2002; Oshagbemi and Gill 2003; Raelin 2012). A related concept of distributed leadership calls for focusing on a collective dynamic, where senior and middle managers and line staff all contribute to managing and leading (Fitzgerald, Ferlie, McGivern and Buchanan 2013; Harris 2008; Hargreaves and Fink 2008). Shared management can be motivated by the administrator's desire to gain support (Oshagbemi 2004), motivate the staff, or extend opportunities to participate in governance (Hargreaves and Fink 2008). In health care, distributed leadership enables service improvements and staff engagement (Rondeau and Wagar 2001; Tomlinson 2012). Nursing home managers, however, tend to prioritize state standards and efficiency over staff empowerment (Deutschman 2005).

More recently, the external orientation of management has been acknowledged. In today's boundary-less context, policies are implemented in multi-organizational arrangements where other entities that may not be fully supportive of individual agencies' missions (Rainey and Steinbauer 1999). O'Toole and Meier's (2011) theory of public management argues that organizational outcomes depend on the manager's ability to exploit and buffer the external influences. While attending to the productive core of their organizations, administrators manage outward and pursue boundary work: protect their organizations' autonomy, build support, procure resources, take advantage of partnerships, co-produce results, engage in external politics, reduce uncertainty, limit potentially hostile forces, and overcome obstacles (Meier and O'Toole 2003; Moore 1995; Rainey and Steinbauer 1999; Yan and Louis, 1999). Similarly, studies on collaborative and network management document managers' involvement in initiation, execution 
and assessment of joint programs and development of joint rules with the external actors (Agranoff and McGuire 2003; Berry et al. 2004; Bryson, Crosby and Stone 2006; Thomson and Perry 2006). Nursing home administrators, similar to other public managers, report spending a considerable amount of time dealing with external issues (Castle, Ferguson and Hughes 2009).

Finally, innovation management, especially relevant to the context of this study, may affect organizational performance. Innovation is a process of changing the established organizational objectives and structures, and how new ideas and practices spread and are "reinvented" throughout social systems has received considerable attention in social science research (Rogers 2003; 2004). Management is viewed as critical in the implementation of innovation (Berry 1994; Gabris, Grenell, Ihrke and Kaatz 1999; Stewart and Kringas 2003). In networked environments, innovation management is multi-pronged: it involves attending to new information, linking actors, reducing complexity, altering preferences, shifting structures, and building norms (O’Toole 1997). Increasingly, managers innovate by tailoring actions to the context (Ortt and van der Duin 2008). In nursing home care, leaders pursuing innovations lower costs and address organizational flaws (Deutschman 2005). The use of new technology (such as medication distribution technology) was found to enhance performance by helping to detect errors and build patient-focused care (Baril, Gascon and Brouillette 2014). The managers' role is important in nursing homes, since nursing home employees are somewhat unfavorable to cultural change (Palmer et al. 2013). We include measures of sharing power, innovation, and external management to explore their effect on care quality and access.

Other Factors Related to Performance. In addition to management, other organizational and environmental factors are related to performance. Organizational ownership plays a central role: theories suggest that public, nonprofit and for-profit sectors play different roles in the 
society and pursue different outcomes (Allison 1982; Rainey, Backoff and Levine 1976). While private organizations are expected to have greater efficiency, less red tape and politics, they are less likely to prioritize legal and political responsiveness (Cohen 2001). Contract failure theory suggests that in markets with notable informational asymetries, public and nonprofit organizations outperform for-profit firms because they do not distribute profits to organizational owners (Hansmann 1987). In health care, public and nonprofit organizations are expected to be more patient- and quality-centered, while for-profits are mainly concerned with cost minimization (Eggleston and Zeckhauser 2002). While nonprofits are instrumental in serving the needs of those different from the average voter, the government sector often steps in when voluntary organizations fail and when equality of consumption is critical (Eggleston and Zeckhauser 2002; Hansmann 1996; Salamon 1987).

Empirical research on public-private differences is mixed, with some evidence of private sector superiority in cost minimization (Hodge 2000; Rainey and Chun 2005). As shown below, in nursing care, public and nonprofit homes deliver better quality of care than for-profits. When the direct measures of management are lacking, ownership is often used as a proxy for different management strategies. This article re-examines the effect of organizational ownership, after separating out the effect of three management variables. Recognizing the importance of multivariate analysis that controls for location and adjusts for environmental risks (Smith 2006), we include other independent variables such as staffing, size, occupancy, affiliation with a hospital, changes in ownership, organizational age, market competition, number of hospitals, home health agencies and hospices in the county, population density, percent of elderly, whites, and those in poverty. We discuss these factors in more detail below.

The Context of Nursing Home Care. As a result of increasing longevity and decreasing 
fertility in the U.S., the quality of long-term care is a salient public policy issue (Government Accountability Office 2015; Kinsella and Velkoff 2001; Thomas 2014). Nursing homes are an important element of the contemporary long-term care systems. These are residences that provide room, meals, and assistance with activities of daily living to individuals with complex chronic care needs. Most nursing homes in the U.S. are for-profit (approximately 65\%), followed by nonprofit and public homes (28\% and 7\%, respectively) (Amirkhanyan et al. 2008). The industry can be characterized by a high degree of publicness for two reasons. ${ }^{10}$ First, federal, state, and local governments are direct providers of nursing care. Originating from public almshouses, nursing homes were created to serve the veterans, elderly, and disabled indigent individuals. While the Medicaid and Medicare programs incentivized private providers to enter the market, numerous governments continued to operate nursing homes (Amirkhanyan 2007; 2008; 2009). Second, federal, state, and local governments are involved in financing and regulating nursing homes. Nursing home care is fairly costly (Levit et al. 2000). According to the Nursing Home Compare (NHC) data used in this study, in 2012, care received by $60 \%$ of nursing home residents was reimbursed by Medicaid, while $16 \%$ were reimbursed by Medicare, and 25\% had private long-term care insurance or paid out-of-pocket. ${ }^{11}$ To be eligible for federal funds, nursing homes must comply with federal and state mandates set forth by the Social Security Act and the Nursing Home Reform Act of 1987 (Kane 1998). The CMS establishes the federal guidelines, while the states enforce them through licensure and inspections. The choice of clients

\footnotetext{
${ }^{10}$ Following Bozeman, in this context, we use the concept of publicness that goes beyond organizations' legal status, but incorporates broader factors, such as the oversight of political actors, and influence of the public and other stakeholders (Bozeman 1987; 2013). As elaborated above, both public and private nursing homes are financed by federal government programs and closely regulated by state government regulators.

${ }^{11}$ The Veteran's Administration nursing home operations account for a small portion of the $25 \%$ of residents not covered by Medicaid and Medicare (Thomas, n.d.). However, we were not able to find any sources specifying the exact share for this market.
} 
by providers, however, is not regulated in private homes (Freeman 2000). The latter motivates our focus to examine access to care as a dimension of performance.

Theories of nursing home markets suggest key differences across ownership (Davis 1993; Scanlon 1980). The traditional assumptions of supply and demand do not work here due to the lack of consumer knowledge, minimal movement across providers, and third party payments. This results in informational asymmetries and limits the effect of reputation. As a result, forprofit "Medicaid mills" serve poorer, sicker and less informed clients and divert resources away from services (Castle and Shea 1998; Harrington, Woolhandler, Mullan, Carrillo and Himmelstein 2001; Lemke and Moos 1989). Meanwhile, nonprofit providers tend to cultivate quality, which helps attract more informed, affluent clients. Nonprofit homes have better physical environment, equipment, and resident control; they evoke fewer complaints and deficiencies (O’Neill, Harrington, Kitchener and Saliba 2003; Santerre and Vernon 2005). In summary, in the private sector, attainment of quality and access is a zero-sum game. A small number of public homes have the safety-net role while providing high quality care (Amirkhanyan et al. 2008).

While data on regulatory violations (or deficiencies) and staffing levels have been publicly available for decades, more recently, in an effort to simplify these indicators, five-star ratings of quality were developed (CMS n.d.a) based on a complex formula using data on staffing, regulatory violations, and other factors (Thomas 2014). Similar to other government inspections, nursing home inspections and star-ratings combine both archival (regulatory) and perceptual (observation-based and self-reported) data (Andrews et al. 2006b). ${ }^{12}$

\footnotetext{
${ }^{12}$ The neutrality and unbiased nature of nursing home performance ratings created by the CMS may be undermined by several factors. First, performance assessment has high financial stakes: this marketplace is fairly litigious, and insurers may consider facility ratings during referrals. These pressures could produce perverse incentives for
} 
Hypotheses. This study examines the relationship of management, ownership, and other organizational factors to nursing home quality and access for Medicaid-funded clients. Existing research on nursing home quality has been primarily based on archival data with no management controls. ${ }^{13}$ Research on "best practices" in nursing care provides limited evidence on the central role of management (Compas, Hopkins and Townsley 2008). As noted in the introduction, our study contributes to the nursing home care literature by examining the effect of three distinct management practices and other factors on numerous measures of care quality and access. The quality of care is a fairly straightforward aspect of performance: higher care quality denotes better performance. Consistent with the past research, we propose the following hypotheses on how three management strategies relate to care quality.

$H_{1}$ : Shared decision-making in organizational management will be associated with improved care quality.

$H_{2}$ : Managers' focus on external influences will be associated with improved care quality.

$H_{3}:$ Innovation management will be associated with improved care quality.

Access to care is more mutifaceted. ${ }^{14}$ From the administrators' perspective, higher dependence on Medicaid as a payment source means a facility is more resource poor, since Medicaid often fall short of covering the costs of care (Angelelli et al. 2003). We hypothesize that administrators who pursue the three managerial strategies under consideration will ensure lower rates of Medicaid admissions:

$H_{4}$ : Shared decision-making in organizational management will be associated with lower Medicaid admissions.

$H_{5}$ : Managers' focus on external influences will be associated with lower Medicaid admissions.

cheating and goal displacement (Thomas 2014). Also, the field is highly political, being influenced by consumer demands to improve care and the industry's attempt to minimize regulation (Edelman, 1997-1998).

${ }^{13}$ These studies suggest that staffing and nonprofit ownership are associated with fewer regulatory violations, while rural location, chain affiliation, size, competition, payment constraints, and percentage of clients on Medicaid are associated with more violations (Amirkhanyan 2008; Townsley, Bech and Pepper 2013; Harrington et al. 2001). ${ }^{14}$ Low-income community members may have a favorable view of higher Medicaid census in local nursing homes. 


\section{$H_{6}$ : Innovation management will be associated with lower Medicaid admissions.}

\section{METHODOLOGY}

Data. We used data from three sources. The NHC is the official public dataset generated by the CMS (CMS, n.d.b) created as a part of the quality assessment and certification process of all Medicaid or Medicare certified providers. State governments enforce national quality standards using trained inspectors who conduct nursing home site visits every nine to fifteen months. The team evaluates a nursing home's compliance with over 180 federal and state regulatory standards in the following categories: quality of care, resident behavior and facility practices, resident assessment, resident rights, physical environment, dietary services, pharmacy services, and administration and regulation. ${ }^{15}$ To verify compliance, state inspectors review clinical and staffing records and interview residents, family members, and staff. A violation identified during a health inspection is recorded as a "health deficiency."

While having perceptual and internal components, NHC is "archival" data: the inspectors are external and are, to the extent possible, detached from the facilities. The inspections are based on a comprehensive tool applied in a standard fashion. ${ }^{16}$ The data are subject to review and appeal and considered an accurate and reliable indicator by scholars (Harrington et al. 2001). NHC is unbalanced facility-inspection level panel data. We have several observations pertaining to each facility, the most recent of which is related to the latest inspection conducted as of 01/01/2014 (i.e., 9-15 months prior to that date). The panel that we used $(\mathrm{N}=15,695)$ contains all Medicare and Medicaid certified nursing homes in the U.S. This dataset was merged with the

\footnotetext{
${ }^{15}$ For a complete listing and explanation of these deficiencies, see CMS (2015a).

${ }^{16}$ Like any inspection-based data, NHC has perceptual components. Inspectors may have ties with certain homes which may influence their assessments. Client and family interviews are also perceptual. Some data used for the 5star ratings are self-reported by nursing homes and are therefore less independent. Star ratings are based on three components: health inspections conducted by outside reviewers, as well as self-reported data on staffing and on eleven different physical and clinical measures of residents' experience (CMS 2015b; Thomas 2014).
} 
Texas A\&M University (TAMU) Nursing Home Administrator (NHA) Survey, the second source of data used in this study (Compton, Calderon \& Meier, 2013).

The TAMU NHA Survey was implemented between 01/2013 and 05/2013. The dates match well with the NHC data. The Survey was administered to all presently operating governmental nursing homes ( $\mathrm{n}=903$ ), and a random sample of 1000 for-profit and 1000 nonprofit homes. We oversampled public homes comprising a small share of the nursing home industry. A total of 725 administrators responded to the survey in three waves, with a response rate of $25 \% .{ }^{17}$ After removing six duplicate records, the number of surveys was $716 .{ }^{18}$ As shown in Appendix A, our sample is similar to the population in terms of key characteristics tabulated by sector: number of beds, number of residents, percentage residents on Medicaid, nursing staff hours, hospital affiliation and both archival measures of quality. Our sample is somewhat more likely to include better performing facilities, which has implications for the generalizability of our findings (see the Discussion section). Appendix A suggests that, despite its modest response rate, our sample is representative of the nursing home population. All fifty states and the District of Columbia were represented both in the fielded sample (2,903 homes) and the final sample (716 homes).

Finally, we used the Area Health Resource Files (AHRF) of the U.S. Bureau of Health Professionals. It includes county-level demographic and socio-economic data as well as information on the prevalence of health care organizations, by county.

Dependent Variables: Quality and Access. We use two alternative archival measures of nursing home quality. The first measure is total number of health deficiencies identified during a

\footnotetext{
${ }^{17}$ The response rate is $20.1 \%$ for for-profit, $25.4 \%$ for nonprofit and $28.9 \%$ for government nursing homes. Our overall response rate compares favorably to a recent nursing home survey in the Netherlands (22\%) reported by Van Eijk and Steen (2015)

${ }_{18}$ Duplicate records occurred as a result of respondents' filling out both the online and hard copy of the survey.
} 
single inspection cycle. It includes both the deficiencies identified during a standard inspection and those identified due to a formal complaint by a party and verified by state surveyors. While theoretically this measure can range between 0 and 188 , in our sample, the range was 0 to 31 $($ mean $=6) .{ }^{19} \mathrm{~A}$ large body of health policy literature has used and validated health deficiencies as a measure of nursing home quality (O'Neill et al. 2003). The second archival measure of quality is the overall 5-star rating, based on a formula incorporating: (a) 5-star health inspection rating, reflecting health deficiencies during the past three years, with recent results weighted more heavily; (b) 5-star staffing rating adjusted for the residents' needs; and (c) 5-star quality rating, reflecting the patients' clinical data. While used in the academic literature, the 5-star rating has received criticism due to its provider-reported components (Thomas 2014). In our sample, the correlation coefficient between the health deficiencies and the overall 5-star rating is -0.52 (5-star rates quality, while deficiencies rate a lack of quality). ${ }^{20}$ As a supplemental measure of quality - perceived nursing home quality - we used six items from the TAMU NHA Survey.

In the regression, we used the factor score for this measure. ${ }^{21}$

To what extent do you agree or disagree with the following statements? (Response categories: strongly agree (4), agree (3), disagree (2) and strongly disagree (1)).

1. Our nursing provides outstanding quality of care.

2. Our facility ensures a clean, safe, home-like and comfortable physical environment.

3. Our nursing home is known for ensuring that the residents' rights are always respected.

4. Our nursing home is known for providing choices to the residents and satisfying their preferences.

5. My nursing home meets the needs of the community it serves.

6. This nursing home is considered to be one of the best of its type in the state.

\footnotetext{
${ }^{19}$ Most homes have few violations: $10 \%$ of inspections had 0 violations, $50 \%$ had $<5$, and $90 \%$ had $<12$.

${ }^{20}$ In the population, this coefficient is -0.54 , and in the fielded sample, it is -0.56 .

${ }^{21}$ Factor analysis suggested using all six items in a single scale was appropriate. Following the Guttman-Kaiser rule, only Factor1 Eigenvalue was above one (2.96), suggesting one factor should be retained. All factors have moderate to high loadings in Factor 1 (for Item1=.75; item2=.70; Item3=.70; Item4=.68; Item5=.65; Item6=.72). The Cronbach's alpha is 0.79 . A predicted score generated from on factor loadings was used as a dependent variable.
} 
We used several measures of access reflecting a home's propensity to serve financially disadvantaged clients. Percent residents on Medicaid ${ }^{22}$ was obtained by the authors from the CMS. Nursing homes with a higher share of residents on Medicaid are argued to be resource poor due to lower reimbursement-to-cost ratios (Castle 2005, 64; The Lewin Group 2002). This measure has been used in the literature (see Amirkhanyan 2008; Amirkhanyan et al. 2008). ${ }^{23}$ We also use four perceptual measures of access from the TAMU NHA Survey. First, variable self-reported percent residents on Medicaid was created:

"Please, specify the percentage of all residents in your nursing home whose care is currently funded by the Medicaid program, Medicare program, or other sources of payment (e.g., out-of-pocket pay or private insurance).

$\%$ residents on Medicaid:

The correlation coefficient between this measure and the "archival" measure is 0.8 , which may suggest recall problems or fluctuation of residents on Medicaid. We also used these three variables (with strongly agree (4), agree (3), disagree (2) and strongly disagree (1) categories):

1. Some cannot afford staying here (Survey item: "Some of our residents have to look for another nursing home because they cannot afford staying here");

2. Difficulty serving the uninsured (Survey item: "Our nursing home has difficulty admitting or serving uninsured clients");

3. Difficulty serving clients on Medicaid (Survey item: "Our nursing home has difficulty admitting and serving residents funded by the Medicaid program").

Independent Variables: Organizational Management. We created three measures reflecting nursing home administrators' management strategies based on the TAMU NHA Survey. First, variable sharing power reflects the administrator's propensity to involve other stakeholders in decision-making. It is the average of the three items (with strongly agree (4), agree (3), disagree (2) and strongly disagree (1) response categories): ${ }^{24}$

\footnotetext{
${ }^{22}$ As opposed to Medicare, private long-term care insurance or private-pay.

${ }^{23}$ It is also similar to the one used by Harrington Meyer (2001), who used Medicaid to private pay ratio in the facility as a measure of access.

${ }^{24}$ Correlation coefficients suggest moderate positive associations between three variables. The Cronbach's alpha is 0.7429, which supports the idea of a single latent factor. In the factor analysis of three items, following the Guttman-
} 
To what extent do you agree or disagree with the following statements?

1. I involve nursing and other non-managerial staff in my nursing home's decisionmaking process.

2. Residents' and families' feedback and outcomes are taken into consideration when revising policies.

3. Non-manager feedback is taken into consideration when revising policies.

Second, innovation reflects a nursing home administrator's propensity to look for and adopt new ideas or practices. This measure is the average of three items: ${ }^{25}$

To what extent do you agree or disagree with the following statements?

1. Our nursing home is always among the first to adopt new technology and practices.

2. We continually search for new opportunities to provide services to our community.

3. Our nursing home is always among the first to adopt new ideas and practices.

Third, managing external influences reflects an administrator's strategies focusing on external

influences. We use the average of the following four items: ${ }^{26}$

To what extent do you agree or disagree with the following statements?

1. My role is to respond to various events and disturbances in the external environment of our nursing home.

2. I always try to limit the influence of external events on the staff and nurses.

3. I strive to control those factors outside the nursing home that could have an effect on my organization.

4. Our nursing home emphasizes the importance of learning from the experience of others. ${ }^{27}$

Ownership and Other Independent Variables. Two nominal variables indicate

ownership status: nonprofit nursing home and public nursing home (NHC). For-profit ownership

\footnotetext{
Kaiser rule, only Factor1 has the Eigenvalue greater than one (1.98315), suggesting that one factor should be retained. All factors have moderate to high loadings in Factor 1 (factor loadings for Item1=.77; item2=.84; Item $3=.83$ ). Independent variables representing this and other management strategies represent averages of items included in the scale.

${ }^{25}$ Correlation matrix between three variables suggest moderate to strong positive associations. The Cronbach's alpha is 0.81 , supporting the idea of a single latent factor. Following the Guttman-Kaiser rule, only Factor1 has the Eigenvalue greater than one (2.17731), suggesting that one factor should be retained. All factors have moderate to high loadings in Factor 1 (factor loadings for Item1=.86; item2=.80; Item3=.90).

${ }^{26}$ The Cronbach's alpha for this scale is 0.59 . Following the Guttman-Kaiser rule, only Factor 1 has the Eigenvalue greater than one (1.82661), suggesting that one factor should be retained. All factors have moderate to high loadings in Factor 1 (factor loadings for Item1=.59; item2=.67; Item3=.81; Item4=.62).

${ }^{27}$ To maximize our sample size, we imputed the mean for the missing values of all items comprising these three management scales. For the three items comprising the "sharing power" scale, percentage of missing cases was $2.38 \%$ (item 1 ); $2.38 \%$ (item2); and 2.24\% (item3). For the three items comprising the "innovation management" scale, percentage of missing cases was $2.38 \%$ (item1); $2.38 \%$ (item2); and $12.03 \%$ (item3). For the four items comprising the "external management" scale, percentage of missing cases was as follows: $3.36 \%$ (item 1 ); $3.64 \%$ (item2); $3.5 \%$ (item3), and $12.4 \%$ (item4).
} 
is the omitted category in all regressions. The variable number of certified beds reflects nursing home's size (NHC). Number of residents reflects the number of clients in a nursing home (NHC). To measure staffing, we use total nurse hours per resident per day including registered, vocational nurse and nurse aide hours (NHC). Hospital affiliated home reflects affiliation with a hospital $(1=y e s, 0=$ no $)(\mathrm{NHC})$. Change of owner indicates whether a facility changed its owner within 12 months (yes $=1$, no $=0)(\mathrm{NHC})$. We use a proxy variable years since certification to measure facility's age (NHC). ${ }^{28}$ For competition, we use the Herfindahl index (Angelelli et al. 2003; Castle 2005): the sum of squared market share percentages (\#beds) for all nursing homes in a county, varying between zero and one (NHC). ${ }^{29}$ Finally, seven county-level measures were created from the AHRF data. Population density per square mile (in 1000s) reflects urbanicity, identified as a key predictor of quality. We also include percent in poverty (below the poverty line), percent elderly (65+), and percent White. Three variables account for alternative medical providers: number of home health agencies, number of hospices and number of hospitals in the county.

Regression Analysis. We use multiple regression analysis to estimate several "quality" and "access" models. In the general form, the models are as follows:

Quality Model

$$
\mathrm{Q}_{2013-2012}=\beta_{0}+\beta_{1} \mathrm{M}_{2013-2012}+\beta_{2} \mathrm{~N}_{2011-2010}+\beta_{3} \mathrm{P}_{2011-2010}+\beta_{4} \mathrm{~A}_{2011-2010}+\beta_{5} \mathrm{X}_{2011-2010}+\mathrm{e}_{1}
$$

\section{Access Model}

$$
\mathrm{A}_{2013-2012}=\delta_{0}+\delta_{1} \mathrm{M}_{2013-2012}+\delta_{2} \mathrm{~N}_{2011-2010}+\delta_{3} \mathrm{P}_{2011-2010}+\delta_{4} \mathrm{Q}_{2011-2010}+\delta_{5} \mathrm{X}_{2011-2010}+\mathrm{e}_{2}
$$

where $Q=$ quality, $A=$ access, $M=$ management, $N=$ nonprofit ownership, $P=$ public ownership, and $X=$ controls.

\footnotetext{
${ }^{28}$ This is an imperfect proxy, as some facilities undergo organizational changes associated with a loss and/or more recent reacquisition of Medicare and/or Medicaid certification.

${ }^{29}$ This index approaches the value of 1 for the least competitive markets with a dominant provider, and zero - for the most competitive and least concentrated markets, with numerous providers that have similar market shares.
} 
The dependent variables are the most recent survey record as of 01/2014, i.e., 2013 and late 2012 survey cycles. The independent variables pertain to one of the previous survey's cycles between 2011 and 2010. Since the TAMU NHA Survey was administered in 2012-2013, all management variables are contemporaneous with the dependent variables. ${ }^{30}$

We use two alternative regression models to examine the total number of health deficiencies. First, we use OLS with robust standard errors (to address heteroscedasticity) and state fixed effects (to alleviate interdependency of observations at the state level). Second, we use a Negative Binomial (NB) model with state fixed effects. The dependent variable - total number of health deficiencies - is a positive count with a positively skewed Poisson distribution. ${ }^{31}$ In the second archival quality model the dependent variable, overall 5-star rating, is ordinal. We used ordered logit with state fixed effects. For the perceptual quality model (perceived nursing home quality), we use OLS with robust standard errors and state fixed effects. The individual factor scores used as a dependent variable reflect individual nursing homes' placement on an underlying factor of "perceived quality." In the archival access model (\%residents on Medicaid), we use OLS with robust standard errors and state fixed effects. We also ran four perceptual access models. OLS is used for self-reported percent on Medicaid. For the remaining three perceptual measures of access (some cannot afford staying here, difficulty serving the uninsured and difficulty serving clients on Medicaid), we use ordered logit.

\section{FINDINGS}

\footnotetext{
${ }^{30}$ In the AHRF, percent elderly, percent in poverty, number of home health agencies and number of hospices in all models were for 2011, while population density, number of hospitals and percent white were for 2010.

${ }^{31}$ We first ran the Poisson regression and examined the goodness of fit. The Pearson chi-square and deviance were greater than one and indicated over-dispersion which violates the assumption of equality of the mean and the variance of the dependent variable imposed by the Poisson model. NB model accommodates overdispersion by including a random term reflecting unexplained between-subject differences (Gardner, Mulvey, and Shaw 1995).
} 
Summary statistics for all variables are in Table 1. Table 2 presents the quality models. We first examine the findings on archival measures: the total number of health deficiencies and the 5-star rating. We find no support for Hypotheses 1 and 2. Hypothesis 3 is confirmed: innovation management - perceived and self-reported search for and adoption of new technologies, ideas, and practices - is associated with a significant reduction in the number of deficiencies in both models. In the fixed effects model, the slope is -1.26 . It is also associated with an increase in the overall 5-star rating. With a one-point increase in innovation levels, a nursing home's ordered log-odds of being in a higher five-star rating category would increase by 0.31, while keeping other variables constant. External management and sharing power are not significant. Additionally, public and nonprofit nursing homes perform significantly better than their for-profit counterparts. They have fewer health deficiencies and a higher 5-star rating. In the fixed effects models, public and nonprofit homes have fewer violations than for-profit facilities by 1.8 and 1.7 , respectively (sig. <0.001). In the nursing home context, these differences are practically important: a single violation may reflect a breach of a regulatory code related to patient quality of life or care, triggering repeat inspections, fines, and lawsuits.

Consistent with the past research, larger nursing homes have more deficiencies and lower star ratings. Meanwhile, occupancy is associated with fewer deficiencies. As the percentage of clients on Medicaid increases, the number of deficiencies increases as well, while the overall 5star rating significantly decreases (but the magnitude is negligible). Finally, higher population density is associated with fewer health deficiencies and higher star rating.

[Tables 1 and 2 about here]

Our secondary goal was to compare the findings across archival and perceptual measures of performance. The perceptual model is only partially consistent with the archival findings. All 
management variables are associated with higher perceived quality. This enhanced estimation of management effect likely suggests common source bias. Public (but not nonprofit) administrators had significantly more positive perceptions of their homes' performance than for-profit administrators. Our findings related to size, occupancy, density, and percentage of Medicaid residents mirror the archival models. Two variables are only significant in the perceptual model: perceived quality declines with organizational age and in counties with lower poverty rate.

The findings on access are presented in Table 3. In the archival model, two management variables are significant. Contrary to Hypothesis 4 , nursing homes where administrators report sharing power (i.e., taking into consideration others' feedback) have a higher percentage of residents on Medicaid (the magnitude is 5.1). We find no evidence of external management being associated with lower access, as Hypothesis 5 suggested. Supporting Hypothesis 6, with 90\% confidence, as innovation increases, percent residents on Medicaid decreases by 3 percentage points. Nonprofit nursing homes have a significantly lower percentage of residents on Medicaid (with a sizeable 10 percentage-point magnitude) compared to for-profit homes. Additionally, as facility age increases, the Medicaid percentage goes up. Staffing is significantly lower in facilities with more Medicaid residents. Finally, as the poverty rate and market competition increase, so does the percent residents on Medicaid.

[Table 3 about here]

Our findings in the perceptual access models are mixed. Respondents in the TAMU NHA Survey were asked to report the current percentage of facility residents on Medicaid. The findings are similar to those in the archival model with two exceptions: management strategies as well as competition are not significant. The remaining three perceptual models of access are less 
informative. ${ }^{32}$ Two models suggest that using power-sharing strategies are associated with limited access for low-income clients. Also, administrators in public and nonprofit nursing homes are significantly less likely to report that their clients cannot afford staying in their facilities or that their homes have difficulty serving the uninsured and Medicaid-funded clients.

\section{DISCUSSION}

This study examines the effect of three management strategies - innovation, shared decision-making, and management of external influences - and other organizational and environmental factors on numerous measures of service quality and access in U.S. nursing homes. Innovation management is associated with significantly fewer health violations assigned by state inspectors and higher facilities' star ratings. Further, innovative management strategies also appear to be positively related to a nursing home's ability to fill their beds with nonMedicaid clients, thus limiting access of low-income or impoverished clients. These findings are tied to the nature of the nursing home industry. Innovation management reflects the managers' propensity to adopt new facility designs, search for new service opportunities, and adopt new ideas, care practices, and technologies. These practices can contribute to the formalization of cutting-edge professional practices that help achieve greater efficiency, improve the quality of care, and reduce the likelihood of violations. These findings are supported by the health care literature on the use of new technologies and their effect on overall organizational performance (Baril et al. 2014). Furthermore, in competitive markets, facilities compete for non-Medicaid clients, whose cost-to-reimbursement ratios are attractive for providers. The focus on innovation may result in a competitive advantage, enhancing the facility's reputation, and attracting healthier, more informed and affluent clients.

\footnotetext{
${ }^{32}$ To improve the fit of these models, we ran simple ordered logit, without controlling for state fixed effects.
} 
Shared decision-making and external management are not associated with service quality. These findings also reflect the context of nursing home care. Taking the time to inform and engage with internal and external stakeholders in decision-making may be viewed as timeconsuming and inconsistent with a management culture of "putting out fires." A recent nursing home study indicates that top managers spend most of their time addressing facilities' short-term, daily operational needs (Castle et al. 2009). Their behavior tends to be reactive: with short-term, rather than long-term agendas. Notably, more centralized (not shared) decision-making is associated with fewer Medicaid clients. The literature is mixed on the effect of distributed leadership in nursing homes (Deutschman 2005; Fitzgerald et al. 2013; Rondeau and Wagar 2001; Tomlinson 2012). Our findings echo Deutschman's (2005) that managers prioritize other factors (e.g., regulations or efficiency) over staff engagement and empowerment. Greater power sharing in homes with more Medicaid clients may suggest that in uncertain, cash-constrained environments, administrators tend to adopt relationship-oriented styles. With the modest significance levels in archival models, more research is needed to understand this relationship.

Our findings on ownership are particularly interesting. After controlling for management, ownership in our models may be capturing management practices related to resource allocation and organizational priorities. In the archival models, nonprofit and public ownership is associated with fewer violations and higher star ratings. Nonprofit homes also serve fewer Medicaid clients. These findings are consistent with the theories of nursing home ownership and performance. Informational asymmetries and limited Medicaid reimbursements determine what appears to be a zero-sum game between quality and access in the private sector. These findings are also consistent with the evidence in the broader organizational management literature suggesting that organizations often pursue conflicting priorities. The for-profit homes are 
incentivized to divert revenues away from quality, while serving older and more disabled Medicaid-funded clients. Meanwhile, the nonprofit homes, a quarter of the industry, cultivate quality by targeting, marketing to, and admitting the more affluent private-pay, privately-insured, or Medicare clients. The latter reflects nonprofits' tendency towards philanthropic individualism and particularism - a propensity to focus on specific target groups, and seek to satisfy their needs irrespective of efficiency considerations (Salamon 2002; Steinberg 2006). Government providers appear to prioritize both dimensions of performance. Importantly, past service to the Medicaid clients is associated with the future prevalence of health deficiencies as well as the star ratings, suggesting that lower revenues undermine future quality.

We supplement our analysis with perceptual measures. In the quality models, all management variables are significant and positive. These findings likely reflect common source bias - the administrators' propensity to favorably report on their practices and successes (Boyne et al. 2006; Meier and O'Toole 2013a). The bias is less likely to affect the access measures, since the difficulty serving the uninsured is unlikely to be thought of as a measure of success by the administrators, who are often financially rewarded for Medicare admissions. Despite some consistency across the archival and perceptual models, some counterintuitive findings in the perceptual models, such as higher perceived quality in less affluent areas, support the idea that these results may be an artifact of omitted variable bias (Meier and O'Toole 2013a).

Additional discrepancies related to the effect of ownership on performance are notable, consistent with past research (Amirkhanyan et al. 2014; Shingler et al. 2008). Theoretically, perceptual measures should correlate with the archival indicators that managers carefully track. Yet the nonprofits' subjective assessments of quality are not significantly different from those in the for-profit sector. Meanwhile, public-sector administrators are in fact reporting higher 
perceived quality than those in the for-profit facilities. Similar differences are present for access to care. While aware of the extent of service to Medicaid recipients, public and nonprofit administrators' responses to the more general questions about access diverge from these findings. Perhaps, reflective of their social missions, nonprofits report providing better access to the uninsured and Medicaid clients compared to for-profits. Public-sector administrators may perceive their homes as a "safety net" in comparison to their for-profit counterparts, despite the fact that their Medicaid admissions are in fact not different from those in the for-profit sector. Even though our measures are fairly specific and meet the general conditions for comparability with the archival measures, we observe discrepancies in terms of the relationship between various factors and the archival and perceptual measures. While the formal indicators are widely available, they do not directly inform the managers' perceptions of quality and access. Consistent with the literature on perceptual measures of performance, our findings suggest that relying exclusively on the internal stakeholders' assessments-in this context or in the broader organizational management literature - is insufficient to understand the scope and the sources of improvements.

Some additional findings merit attention to help understand the sources of improvement in organizational performance. Consistent with the argument that resources are the most likely sources of performance improvements, having more non-Medicaid clients (and hence, higher revenues) is associated with fewer violations and higher star ratings. The effect of population density suggests that higher care quality is harder to achieve in less populated areas. Additionally, consistent with the past nursing home care literature, larger nursing homes provide lower quality of care. Smaller nursing homes may be more effective at creating unique environments and personalizing care for their residents (Amirkhanyan 2008). 
We reflect upon our use of hybrid data, its merits and limits. The key advantage, as noted earlier, is in connecting "the black box" of management and the richness of the internal organizational context to the performance data generated in a standardized fashion by independent stakeholders (Boyne et al. 2006). The TAMU NHA Survey was designed and administered after a carefully considering the archival measures of the NHC data, resulting in perceptual data tailored to the archival data. ${ }^{33}$ Clearly, primary data collection may not always be feasible or may present selection challenges due to lower response rates. Merging two secondary data sets into a hybrid data set, in turn, may present its own unique challenges.

We note several limitations of this study. Our findings suggest that the policy context is key in understanding what strategies are related to performance. This study is conducted in a market with high asset specificity, dependent clientele, extensive government subsidies and regulation, and relatively low service measurability. The use of formal long-term care is higher in countries and communities with a higher employment rate, higher job-related mobility, better retirement benefits, and, therefore, higher prevalence of nuclear families. Our findings on management, thus, may be more generalizable to similar markets ${ }^{34}$ and less generalizable to other policy fields.

\footnotetext{
${ }^{33}$ The TAMU NHA Survey, administered by the authors of this study, includes perceptual measures of performance developed to (1) be specific in referring to various aspects of performance, and (2) generally reflect the archival measures included in the NHC data to allow us to compare results across measures. Thus, the NHC data set includes information on the percentage of residents receiving Medicaid. In the NHA Survey, we also asked respondents for the same information. (Additionally, we asked three alternative questions on access). The regulatory violations in the NHC data are based on various mandates pertaining, broadly, to quality of care, resident behavior and facility practices, resident rights, physical environment, and others. The subjective nursing home performance scale in the NHA Survey includes several (albeit, limited, by virtue of survey length limitations) questions touching upon several key categories of care quality, facility condition, residents' rights, and others.

${ }^{34}$ These may include fields such as substance abuse, mental health, or developmental disabilities services, familycentered social services, child care, or home health care. Nonetheless, important differences across these fields should not be disregarded. None of these services require the level of technological and scientific sophistication prevalent in nursing homes. Their financing and regulation, mostly done through state and local government contracts and contract monitoring, is also quite different from the formal state inspection, licensure and reimbursement processes in nursing home care.
} 
Furthermore, while our use of hybrid data helps avoid common source bias by using archival data along with perceptual managerial measures, the latter measures may be subject to positivity and social desirability bias. The online/mail-in character of the TAMU NHA Survey may help minimize this concern. Additionally, as noted earlier, our sample is more likely to include better performing facilities, and hence the effect of management that we observe may be more pronounced in those homes. Finally, while we control for a wide range of factors typically included in the analysis of nursing home quality, we cannot exclude the possibility of omitted variable bias. Thus, we lack data on financial performance of nursing homes which would present additional interesting directions for this study. (The percentage of residents funded by Medicaid we include here could serve as an indirect measure of facility revenues.)

Finally, we note two directions for further research. Boyne (2003) finds as an important source of public sector improvement - government regulation. While our current article uses two products of the regulatory process - deficiencies and star ratings - we do not directly consider the process of regulation and the administrators' relevant experiences and perceptions (see Amirkhanyan, Meier and O'Toole 2017). The latter is extremely important in the heavily regulated U.S. nursing home context. Understanding how government regulation is perceived by public, nonprofit, and for-profit administrators and exploring the influence of these experiences and perceptions on the facilities' performance may inform our understanding of how government quality assurance and assessment influence service quality.

Furthermore, our perceptual measures of quality come from a single source - the nursing home administrators. Subjective assessments of organizational performance can come from numerous external and internal constituencies that are likely to have different needs and perspectives of the value of public services (Connolly, Conlon and Deutsch 1980). Thus, a more 
comprehensive analysis of performance would incorporate other assessments, for instance those coming from the organizational clients. While we do not have data on client satisfaction, some NHC deficiencies are associated with client complaints. As a next step, we plan on exploring complaint-based violations and comparing them with those based on the standard facility surveys conducted by state inspectors. 


\section{TABLES}

Table 1. Dependent and Independent Variables. Descriptive Statistics.

\begin{tabular}{lrrrrr}
\hline Dependent Variables & Mean & St.D. & Min & Max & Obs \\
\hline Archival Quality Measures (NHC) & & & & & \\
$\quad \begin{array}{l}\text { Total number of health deficiencies } \\
\quad \text { Overall 5-star rating* }\end{array}$ & 5.87 & 5.04 & 0 & 31 & 713 \\
$\begin{array}{l}\text { Perceptual Quality Measures (TAMU Survey) } \\
\quad \text { Perceived nursing home quality }\end{array}$ & 3.65 & 1.24 & 1 & 5 & 682 \\
Archival Access Measures (NHC) & 3.62 & 0.37 & 2.17 & 4 & 689 \\
$\quad \begin{array}{l}\text { Percent residents on Medicaid } \\
\text { Perceptual Access Measures (TAMU Survey) }\end{array}$ & 57.90 & 22.65 & 0 & 100 & 715 \\
$\quad$ Self-reported percent residents on Medicaid & 58.65 & 23.97 & 0 & 100 & 594 \\
$\quad$ Some cannot afford staying here** & 1.83 & 0.90 & 1 & 4 & 692 \\
$\quad$ Difficulty serving the uninsured*** & 1.65 & 0.79 & 1 & 4 & 699 \\
$\quad$ Difficulty serving clients on Medicaid**** & 2.67 & 0.95 & 1 & 4 & 693
\end{tabular}

\begin{tabular}{lrrrrr}
\hline Independent Variables & & & & & \\
\hline Nonprofit nursing home (NHC) & 0.35 & $\mathrm{n} / \mathrm{a}$ & 0.0 & 1.0 & 715 \\
Public nursing home (NHC) & 0.34 & $\mathrm{n} / \mathrm{a}$ & 0.0 & 1.0 & 715 \\
Management: Sharing power (TAMU Survey) & 3.46 & 0.45 & 2.0 & 4.0 & 715 \\
Management: Innovation (TAMU Survey) & 2.83 & 0.60 & 1.0 & 4.0 & 715 \\
Management: Managing ext. influences (TAMU Survey) & 3.00 & 0.42 & 1.8 & 4.0 & 715 \\
Number of certified beds (NHC) & 103.48 & 72.38 & 9.0 & 720.0 & 706 \\
Number of residents (NHC) & 89.03 & 67.16 & 2.0 & 664.0 & 706 \\
Total nursing hours per resident per day (NHC) & 4.17 & 1.81 & 1.5 & 27.7 & 706 \\
Hospital affiliated home (NHC) & 0.11 & $\mathrm{n} / \mathrm{a}$ & 0.0 & 1.0 & 706 \\
Change of owner during past 12 month (NHC) & 0.03 & $\mathrm{n} / \mathrm{a}$ & 0.0 & 1.0 & 706 \\
Years since certification (NHC) & 21.34 & 11.90 & 0.0 & 44.0 & 706 \\
Population density (in 1000s) per sq. mile (AHRF) & 0.77 & 2.67 & 0.0 & 35.4 & 714 \\
Percent elderly (AHRF) & 15.32 & 4.11 & 6.6 & 35.1 & 714 \\
Percent in poverty (AHRF) & 15.59 & 5.31 & 4.0 & 41.8 & 714 \\
Number of home health agencies (AHRF) & 19.08 & 79.88 & 0.0 & 677.0 & 714 \\
Number of hospices (AHRF) & 3.70 & 9.20 & 0.0 & 113.0 & 714 \\
Number of hospitals (AHRF) & 5.69 & 10.76 & 0.0 & 111.0 & 714 \\
Herfindahl index of competition (NHC) & 0.29 & 0.29 & 0.0 & 1.0 & 708 \\
Percent White (AHRF) & 81.89 & 15.73 & 17.4 & 98.9 & 714 \\
\hline
\end{tabular}

*7\% of nursing homes had a 1 star rating; $14 \%$ : 2 stars; $17 \%$ : 3 stars; $31 \%: 4$ stars; $31 \%$ : 5 stars. $* 2.43 \%$ strongly agreed; $12.16 \%$ agreed, $33.19 \%$ disagreed and $52.22 \%$ strongly disagreed. $* * * 21.93 \%$ strongly agreed; $35.64 \%$ agreed, $30.30 \%$ disagreed and $12.12 \%$ strongly disagreed. $* * * * 7.8 \%$ strongly agreed; $10.4 \%$ agreed, $39 \%$ disagreed and $42.77 \%$ strongly disagreed.

Note 1. "NHC" Nursing Home Compare; "AHRF" Area Health Resource File.

Note 2. While in the regression we use individual factor scores for perceived nursing home quality, in Table 1, we report the more intuitively clear averages of items comprising each variable. 
Table 2. Quality Models: Measures from Archival and Perceptual Data.

\begin{tabular}{|c|c|c|c|c|c|c|c|c|c|c|c|c|c|}
\hline \multirow{4}{*}{ Independent Variables } & \multicolumn{10}{|c|}{ A R C H I V A L } & \multirow{3}{*}{\multicolumn{3}{|c|}{$\begin{array}{c}\text { P E R C E P T U A L } \\
\begin{array}{c}\text { D.V.: Perceived } \\
\text { nursing home quality }\end{array} \\
\text { Fixed Effects Model }\end{array}$}} \\
\hline & \multicolumn{7}{|c|}{ Total number of health deficiencies } & \multirow{2}{*}{\multicolumn{3}{|c|}{$\begin{array}{c}\text { Overall 5-star } \\
\text { rating }\end{array}$}} & & & \\
\hline & \multicolumn{3}{|c|}{$\begin{array}{c}\text { Fixed Effects } \\
\text { Model }\end{array}$} & \multicolumn{4}{|c|}{ Negative Binomial Model } & & & & & & \\
\hline & $\mathrm{b}$ & S.E. & sig. & $\mathrm{b}$ & OR & S.E. & sig. & $\mathrm{b}$ & S.E. & sig. & $\mathrm{b}$ & S.E. & sig. \\
\hline \multicolumn{14}{|l|}{ Nursing Home Variables } \\
\hline Nonprofit nursing home & -1.70 & 0.45 & $* * *$ & -0.32 & 0.73 & 0.08 & $* * *$ & 0.98 & 0.20 & $* * *$ & 0.09 & 0.11 & \\
\hline Public nursing home & -1.84 & 0.52 & $* * *$ & -0.33 & 0.72 & 0.09 & $* * *$ & 0.81 & 0.21 & $* * *$ & 0.27 & 0.11 & $* *$ \\
\hline Management: Sharing power & 0.61 & 0.43 & & 0.09 & 1.09 & 0.07 & & 0.24 & 0.18 & & 0.22 & 0.07 & $* * *$ \\
\hline Management: Innovation & -1.28 & 0.32 & $* * *$ & -0.22 & 0.81 & 0.05 & $* * *$ & 0.31 & 0.13 & $* *$ & 0.52 & 0.05 & $* * *$ \\
\hline Management: External management & -1.01 & 0.66 & & -0.11 & 0.90 & 0.08 & & 0.11 & 0.19 & & 0.32 & 0.09 & $* * *$ \\
\hline Number of certified beds & 0.03 & 0.01 & $* * *$ & 0.01 & 1.01 & 0.00 & $* *$ & -0.02 & 0.00 & $* * *$ & -0.01 & 0.00 & $* * *$ \\
\hline Number of residents & -0.02 & 0.01 & $*$ & 0.00 & 1.00 & 0.00 & & 0.01 & 0.01 & $* *$ & 0.01 & 0.00 & $* * *$ \\
\hline Total nursing hours per resident per day & 0.03 & 0.14 & & 0.01 & 1.01 & 0.02 & & 0.08 & 0.06 & & -0.01 & 0.04 & \\
\hline Percent residents on Medicaid & 0.02 & 0.01 & $* *$ & 0.00 & 1.00 & 0.00 & $* *$ & -0.01 & 0.00 & $* * *$ & 0.00 & 0.00 & $* *$ \\
\hline Hospital affiliated home & -0.05 & 0.56 & & 0.01 & 1.01 & 0.11 & & -0.12 & 0.27 & & 0.17 & 0.11 & \\
\hline Change of owner during past 12 month & -0.70 & 0.93 & & -0.03 & 0.97 & 0.20 & & -0.06 & 0.49 & & -0.31 & 0.25 & \\
\hline Years since certification & 0.00 & 0.02 & & 0.00 & 1.00 & 0.00 & & 0.01 & 0.01 & & -0.01 & 0.00 & $* *$ \\
\hline \multicolumn{14}{|l|}{ County-level Variables } \\
\hline Population density & -0.15 & 0.06 & $* *$ & -0.03 & 0.97 & 0.02 & $*$ & 0.12 & 0.04 & $* * *$ & -0.01 & 0.01 & $* *$ \\
\hline Percent elderly & -0.04 & 0.05 & & -0.01 & 0.99 & 0.01 & & 0.02 & 0.02 & & 0.00 & 0.01 & \\
\hline Percent in poverty & 0.06 & 0.05 & & 0.01 & 1.01 & 0.01 & & -0.03 & 0.02 & & 0.02 & 0.01 & * \\
\hline Herdindahl index of competition & 1.32 & 0.79 & & 0.23 & 1.26 & 0.14 & & 0.01 & 0.36 & & -0.10 & 0.15 & \\
\hline Intercept & 8.67 & 2.50 & $* * *$ & & & & & & & & -3.03 & 0.31 & $* * *$ \\
\hline $\mathrm{N}$ & 703 & & & 703 & & & & 672 & & & 679 & & \\
\hline R Square (or Pseudo R Square) & 0.06 & & & 0.05 & & & & 0.09 & & & 0.21 & & \\
\hline Prob > F (or Chi Square) & 0.00 & & & 0.00 & & & & 0.00 & & & 0.00 & & \\
\hline Note: $* * *=\operatorname{sig}<0.01 ; * *=\operatorname{sig}<0.05 ; * \mathrm{~s}$ & & & & & & & & & & & & & \\
\hline
\end{tabular}


Table 3. Access Models: Measures from Archival and Perceptual Data.

\begin{tabular}{|c|c|c|c|c|c|c|c|c|c|c|c|c|c|c|c|}
\hline & \multirow{2}{*}{\multicolumn{3}{|c|}{$\begin{array}{c}\text { A R C H I V A L } \\
\text { Percent residents } \\
\text { on Medicaid }\end{array}$}} & \multicolumn{12}{|c|}{ P ER CEPTUAL } \\
\hline & & & & $\begin{array}{r}\text { Self-r } \\
\text { resi }\end{array}$ & $\begin{array}{l}\text { eported } \\
\text { dents on }\end{array}$ & $\%$ & $\begin{array}{r}\text { Some c } \\
\text { stay } \\
\end{array}$ & $\begin{array}{l}\text { innot af } \\
\text { ing here }\end{array}$ & ford & $\begin{array}{r}\text { Difficu } \\
\text { the ul } \\
\end{array}$ & $\begin{array}{l}\text { Ity serv } \\
\text { insure }\end{array}$ & & $\begin{array}{r}\text { Difficul } \\
\text { clients of }\end{array}$ & $\begin{array}{l}\text { y servin } \\
\text { Medica }\end{array}$ & caid \\
\hline \multirow[t]{2}{*}{ Independent Variables } & \multicolumn{3}{|c|}{$\begin{array}{c}\text { Fixed Effects } \\
\text { Model }\end{array}$} & \multicolumn{3}{|c|}{$\begin{array}{c}\text { Fixed Effects } \\
\text { Model }\end{array}$} & \multicolumn{3}{|c|}{ Ordered Logit } & \multicolumn{3}{|c|}{ Ordered Logit } & \multicolumn{3}{|c|}{ Ordered Logit } \\
\hline & $\mathrm{b}$ & S.E. & sig. & $\mathrm{b}$ & S.E. & sig. & $\mathrm{b}$ & S.E. & sig. & $\mathrm{b}$ & S.E. & $\overline{\text { sig. }}$ & $\mathrm{b}$ & S.E. & $\overline{\text { sig. }}$ \\
\hline \multicolumn{16}{|l|}{ Nursing Home Variables } \\
\hline Nonprofit nursing home & -10.10 & 1.86 & $* * *$ & -9.42 & 2.04 & $* * *$ & -0.49 & 0.20 & $* *$ & -0.59 & 0.19 & $* * *$ & 0.30 & 0.19 & \\
\hline Public nursing home & -2.05 & 1.97 & & 0.34 & 2.77 & & -0.81 & 0.21 & $* * *$ & -1.00 & 0.20 & $* * *$ & -0.56 & 0.21 & $* * *$ \\
\hline Management: Sharing power & 3.22 & 1.70 & $*$ & 1.98 & 1.91 & & -0.35 & 0.18 & $*$ & -0.11 & 0.17 & & -0.53 & 0.18 & $* * *$ \\
\hline Management: Innovation & -2.36 & 1.25 & $*$ & -0.47 & 1.52 & & 0.14 & 0.13 & & 0.12 & 0.13 & & 0.05 & 0.13 & \\
\hline Management: External Management & 1.40 & 1.95 & & 1.77 & 2.55 & & -0.06 & 0.20 & & 0.13 & 0.19 & & -0.24 & 0.20 & \\
\hline Number of certified beds & 0.07 & 0.05 & & 0.04 & 0.07 & & 0.00 & 0.00 & & 0.00 & 0.00 & & 0.00 & 0.00 & \\
\hline Number of residents & -0.03 & 0.05 & & 0.01 & 0.07 & & -0.01 & 0.01 & & 0.00 & 0.00 & & -0.01 & 0.00 & \\
\hline Total nursing hours per resident per day & -1.39 & 0.52 & $* * *$ & -2.33 & 0.47 & $* * *$ & 0.06 & 0.04 & & -0.02 & 0.04 & & 0.02 & 0.04 & \\
\hline Total number of health deficiencies & 0.23 & 0.17 & & 0.13 & 0.15 & & 0.00 & 0.01 & & 0.00 & 0.01 & & -0.02 & 0.01 & \\
\hline Hospital affiliated home & -2.39 & 3.30 & & 0.49 & 3.90 & & 0.40 & 0.26 & & -0.02 & 0.24 & & -0.04 & 0.26 & \\
\hline Change of owner during past 12 month & -1.82 & 3.12 & & 0.88 & 4.55 & & 0.17 & 0.46 & & 0.31 & 0.48 & & 0.02 & 0.46 & \\
\hline Years since certification & 0.28 & 0.10 & $* * *$ & 0.22 & 0.11 & $* *$ & 0.00 & 0.01 & & 0.00 & 0.01 & & 0.00 & 0.01 & \\
\hline \multicolumn{16}{|l|}{ County-level Variables } \\
\hline Population density & -0.67 & 0.41 & & -0.60 & 0.41 & & 0.04 & 0.03 & & 0.00 & 0.03 & & 0.07 & 0.03 & $* *$ \\
\hline Percent elderly & 0.20 & 0.25 & & 0.21 & 0.34 & & 0.00 & 0.02 & & -0.01 & 0.02 & & -0.05 & 0.02 & $* *$ \\
\hline Percent in poverty & 0.94 & 0.21 & $* * *$ & 1.22 & 0.19 & $* * *$ & 0.00 & 0.02 & & 0.01 & 0.02 & & -0.05 & 0.02 & $* * *$ \\
\hline Number of home health agencies & 0.01 & 0.02 & & 0.01 & 0.02 & & 0.00 & 0.00 & & 0.00 & 0.00 & & 0.00 & 0.00 & \\
\hline Number of hospices & -0.06 & 0.30 & & -0.22 & 0.31 & & 0.00 & 0.02 & & 0.04 & 0.02 & $* *$ & 0.00 & 0.02 & \\
\hline Number of hospitals & -0.04 & 0.33 & & -0.09 & 0.33 & & 0.02 & 0.02 & & -0.02 & 0.02 & & -0.02 & 0.02 & \\
\hline Herfindahl index of competition & 5.92 & 2.79 & $* *$ & 1.47 & 4.02 & & 0.39 & 0.31 & & 0.19 & 0.31 & & 0.29 & 0.32 & \\
\hline Percent White & 0.11 & 0.11 & & 0.12 & 0.12 & & 0.00 & 0.01 & & 0.00 & 0.01 & & 0.00 & 0.01 & \\
\hline Intercept & 20.14 & 15.06 & & 19.22 & 16.29 & & & & & & & & & & \\
\hline $\mathrm{N}$ & 679 & & & 569 & & & 663 & & & 657 & & & 656 & & \\
\hline R Square (or Pseudo R Square) & 0.20 & & & 0.21 & & & 0.03 & & & 0.03 & & & 0.04 & & \\
\hline Prob > F (or Chi Square) & 0.00 & & & 0.00 & & & 0.01 & & & 0.00 & & & 0.00 & & \\
\hline Note $1: * * *=\operatorname{sig}<0.01 ; * *=\operatorname{sig}<0.05 ; * \operatorname{si}$ & & & & & & & & & & & & & & & \\
\hline
\end{tabular}

Note 2: State dummies were not used in Ordered Logit models, as the fit of those models was qeustionable. 


\section{BIBLIOGRAPHY}

Addicott, Rachael, and Ewan Ferlie. 2006. A qualitative evaluation of public sector organizations: Assessing organizational performance in healthcare. In Public Service Performance: Perspectives on Measurement and Management, ed. George A. Boyne, Kenneth J. Meier, Laurence J. O’Toole, Jr., and Richard M. Walker, 55-73. Cambridge, MA: Cambridge University Press.

Agranoff, Robert, and Michael McGuire. 2003. Collaborative public management: New strategies for local governments. Washington, DC: Georgetown University Press.

Allison, Graham, Jr. 1982. Public and private management: Are they fundamentally alike in all unimportant respects? In Current Issues in Public Administration, ed. Frederick Lane, 13-33. New York: St. Martin's Press.

Amirkhanyan, Anna 2007. The smart-seller challenge: The determinants of privatizing public nursing homes. Journal of Public Administration Research and Theory, 17 (3): 501-527. 2008. Privatizing public nursing homes: Examining the effect on quality and access. Public Administration Review, 68(4): 665-680. 2009. Rejecting privatization: Case study analysis of local government decision-making. The Journal of Public Management and Social Policy, 15(1): 163-192.

Amirkhanyan, Anna, Hyun Joon Kim, and Kristina Lambright. 2008. Does the public sector outperform the nonprofit and for-profit sectors? Evidence from a national panel study on nursing home quality and access. Journal of Policy Analysis and Management, 27(2): 326-353. . 2014. The Performance Puzzle: Understanding the Factors Influencing Alternative Dimensions of Performance, Journal of Public Administration Research and Theory, 24 (1): 1-34.

Amirkhanyan, Anna, Kenneth J. Meier, and Laurence J. O'Toole, Jr. 2017. Managing in the regulatory thicket: Regulation legitimacy and expertise. Public Administration Review DOI: 10.1111/puar.12591.

Andrews, Rhys, George A. Boyne, and Richard M. Walker. 2006a. Strategy content and organizational performance: An empirical analysis. Public Administration Review, January/February, 52-62. . 2006b. Subjective and objective measures of organizational performance: An empirical exploration. In Public Service Performance: Perspectives on Measurement and Management, ed. George A. Boyne, Kenneth J. Meier, Laurence J. O’Toole, Jr., and Richard M. Walker, 14-34. Cambridge, MA: Cambridge University Press.

Angelelli, Joseph, Vincent Mor, Orna Intrator, Zhanlian Feng, and Jacqueline Zinn. 2003. Oversight of nursing homes: Pruning the tree or just spotting bad apples? The Gerontologist 43 (Special Issue II): 67-75.

Baril, Chantal, Gascon, Viviane, and Christel Brouillette (2014). Impact of technological innovation on a nursing home performance and on the medication-use process safety. Journal of Medical Systems, 38 (22): 1-12.

Berry, Frances. 1994. Innovation in public management: The adoption of strategic planning. Public Administration Review, 54 (1): 322-330.

Berry, Frances, Ralph S. Brower, Sang Ok Choi, Wendy Xinfang Goa, HeeSoun Jang, Myungjung Kwon6 and Jessica Word. 2004. Three traditions of network research: What the public management research agenda can learn from other research communities. Public Administration Review, 64 (5): 539-552.

Bommer, William, H., Jonathan, L. Johnson, Gregory, Rich, Philip Podsakoff, and Scott Mackenzie. 1995. On the interchangeability of objective and subjective measures of employee performance: A meta-analysis. Personnel Psychology, 48: 587-605.

Boyne, George A. 2002. Concepts and Indicators of Local Authority Performance: An Evaluation of the Statutory Frameworks in England and Wales. Public Money and Management, 22 (2): 17-24. . 2003. Sources of public service improvement: A critical review and research agenda. Journal of Public Administration Research and Theory, 13 (3): 367-394.

Boyne, George A., Kenneth J. Meier, Laurence, J. O’Toole Jr, and Richard M. Walker. 2006. Public service performance: Perspectives on measurement and management. Cambridge, MA: Cambridge University Press.

Boyne, George A., and Kenneth J. Meier 2009. Environmental turbulence, organizational stability, and public service performance. Administration and Society, 40: 799-824.

Bozeman, B. 1987. All organizations are public. San Francisco, CA: Jossey-Bass. 
2013. What organization theorists and public policy researchers can learn from one another: Publicness theory as a case-in-point, Organization Studies, 34 (2): 169-188.

Brewer, Gene A. and Sally Coleman Selden. 2000. Why elephants gallop: Assessing and predicting organizational performance in federal agencies. The Journal of Public Administration Research and Theory, 10 (4): 685711.

Brewer, Gene A. 2006. All measures of performance are subjective: More evidence on us federal agencies. In Public service performance: Perspectives on measurement and management, ed. George A. Boyne, Kenneth J. Meier, Laurence J. O’Toole, Jr., and Richard M. Walker, 35-54. Cambridge, MA: Cambridge University Press.

Brown, Karin, and Philip Coulter. 1983. Subjective and objective measures of police service delivery. Public Administration Review, 43(1): 50-58.

Bryson, John M., Barbara C. Crosby and Melissa Middleton Stone. 2006. The design and implementation of crosssector collaborations: Propositions from the literature. Public Administration Review, 66 (S1): 44-55.

Castle, Nicolas G. 2005. Nursing home closures and quality of care. Medical Care Research and Review, 62 (1): 111-32.

Castle, Nicolas G., Ferguson, J. C., and Hughes, K. 2009. Humanism in nursing homes: The impact of top management. Journal of Health and Human Services Administration, Spring, 483-516.

Castle, Nicholas G. and Dennis Shea. 1998. The effects of for-profit and not-for-profit facility status on the quality of care for nursing home residents with mental illnesses. Research on Aging, 20(2): 246-263.

Centers for Medicare and Medicaid Services (n.d.a). Five-Star Quality Rating System. Retrieved 10/16/2014 from the web site: http://www.cms.gov/Medicare/Provider-Enrollment-andCertification/CertificationandComplianc/FSQRS.html

(n.d.b). Official Nursing Home Compare Data. Retrieved 10/16/2014 from the web site: https://data.medicare.gov/data/nursing-home-compare

(2015a). State Operations Manual. Appendix PP. Rev. 149, 10-09-2015. Retrieved February 1, 2016 from the web site: https://www.cms.gov/Regulations-andGuidance/Guidance/Manuals/downloads/som107ap_pp_guidelines_ltcf.pdf

(2015b). Design for Nursing Home Compare Five-Star Quality Rating System. Technical Users' Guide. Retrieved February 1, 2016 from the web site: https://www.cms.gov/medicare/provider-enrollment-andcertification/certificationandcomplianc/downloads/usersguide.pdf

Cohen, Steven. 2001. A strategic framework for devolving responsibility and function from government to the private sector. Public Administration Review, 61 (4): 432-440.

Compas, Carol, Kimberly Hopkins, and Elaine Townsley. 2008. Best practices in implementing and sustaining quality of care. Research in Gerontological Nursing, 1(3): 209-216.

Compton, Mallory, Polly Calderon, and Kenneth J. Meier. 2013. National Nursing Home Survey. Project for Equity, Representation and Governance, Texas A\&M University.

Connolly, Terry, Edward J. Conlon and Stuart Jay Deutsch. 1980. Organizational effectiveness: A multiple constituency approach. Academy of Management Review, 5(2): 211-218.

Davis, Mark A. 1993. Nursing home ownership revisited: Market, costs, and quality relationships. Medical Care 31(11): 1062-1068.

Dearden, Philip, Mike Carter, Jim Davis, Robert Kowalski and Mary Surridge. 1999. Icitrap - an experiential training exercise for examining participatory approaches to project management. Public Administration and Development, 19 (1): 93-104.

Deutschman, Marian T. 2005. An ethnographic study of nursing home culture to define organizational realities of culture change. Journal of Health and Human Services Administration, 28 (1/2): 246-281.

Edelman, Toby S. 1997-1998. The politics of long-term care at the federal level and implications for quality. Generations, 21(4): 37-41.

Eggleston, Karen, and Richard Zeckhauser. 2002. Government contracting for health care. In Market-Based Governance, ed. John Donahue and Joseph Nye Jr., 29-65. Washington, DC: Brookings Institution Press. 
Favero, Nathan and Justin B. Bullock. 2015. How (not) to solve the problem: An evaluation of scholarly responses to common source bias. Journal of Public Administration Research and Theory 25(1): 285308.

Fitzgerald, Louise, Ewan Ferlie, Gerry McGivern and D. Buchanan. 2013. Distributed leadership patterns and service improvement: evidence and argument from English healthcare. The Leadership Quarterly, 24 (1): 227-239.

Forbes, Melissa, Carolyn Hill, and Laurence Lynn. 2006. Public management and government performance: an international review. In Public Service Performance: Perspectives on Measurement and Management, ed. George A. Boyne, Kenneth J. Meier, Laurence J. O’Toole, Jr., and Richard M. Walker, 254-274. Cambridge, MA: Cambridge University Press.

Freeman, Jody. 2000. The contracting state. Florida State University Law Review, 28: 155-214.

Gabris, Gerald T., Keenan Grenell, Douglas Ihrke and James Kaatz. 1999. Managerial innovation as affected by administrative leadership and policy boards. Public Administration Quarterly: 23(2): 223-249.

Gardner, William, Edward Mulvey, and Esther Shaw. 1995. Regression analysis of counts and rates: Poisson, overdispersed Poisson, and negative binomial models. Psychological Bulletin, 118(3): 392-404.

Government Accountability Office (GAO). 2015. Nursing home quality: CMS should continue to improve data and oversight. GAO-16-33. Washington, D.C.: U.S. Government Printing Office.

Gronn, Peter. 2008. The Future of Distributed Leadership. Journal of Educational Administration, 46(2): 141-158.

Hansmann, Henry. 1987. Economic theories of nonprofit organizations. In The nonprofit sector: A research handbook, ed. W.W. Powell, 27-42. New Haven, CT: Yale University Press.

1996. The changing roles of public, private, and nonprofit enterprise in education, health care, and other human services. In Individual, and social responsibility: Child care, education, medical care, and longterm care in America, ed. V.R. Fuchs, 245-275. Chicago: The University of Chicago Press.

Hargreaves, Andy and Dean Fink. 2008. Distributed Leadership" democracy or delivery? Journal of Educational Administration, 46 (2): 229-240.

Harrington, Charlene, Steffie Woolhandler, Joseph Mullan, Helen Carrillo, and David Himmelstein. 2001. Does Investor Ownership of Nursing Homes Compromise the Quality of Care? American Journal of Public Health, 91(1): 1452- 1455.

Harrington Meyer, Madonna. 2001. Medicaid reimbursement rates and access to nursing homes. Implications for gender, race, and marital status. Research on Aging, 23(5): 532-551.

Harris, Alma. 2008. Distributed leadership: According to the evidence. Journal of Educational Administration, 46 (2): $172-188$.

Heinrich, Carolyn, J. 2012. How credible is the evidence, and does it matter? An analysis of the program assessment rating tool. Public Administration Review, 72(1): 123-134.

Heinrich, Carolyn J. and Gerald Marschke. 2010. Incentives and their dynamics in public sector performance management systems. Journal of Policy Analysis and Management 29(1): 183-208.

Hodge, Graeme A. 2000. Privatization: An international review of performance. Boulder, CO: Westview Press.

Kane, Richard. 1998. Assuring quality in nursing home care. Journal of the American Geriatrics Society, 46: 232237.

Kelly, Janet M. and David Swindell. 2002. A multiple-indicator approach to municipal service evaluation: Correlating performance measurement and citizen satisfaction across jurisdictions. Public Administration Review, 62(5): 610-621.

Kenis, Patrick. 2006. Performance control and public organizations. In Public Service Performance: Perspectives on Measurement and Management, ed. George A. Boyne, Kenneth J. Meier, Laurence J. O’Toole, Jr., and Richard M. Walker, 113-129. Cambridge, MA: Cambridge University Press.

Kim, Soonhee. 2002. Participative management and job satisfaction: Lessons for management leadership. Public Administration Review, 62 (2): 231-241.

Kinsella, Kevin and Victoria Velkoff. 2001. An aging world: 2001. International population reports. Washington, D.C.: US Department of Health and Human Services, National Institutes of Health, National Institute on Aging, U.S. Department of Commerce, Economics and Statistics Administration, and U.S. Census Bureau. P95/01-1 
Lemke, Sonne and Rudolf H. Moos. 1989. Ownership and Quality of Care in Residential Facilities for The Elderly. The Gerontologist, 29(2): 209-215.

Levit, Katharine, Cathy Cowan, Helen Lazenby, Arthur Sensenig, Patricia McDonnell, Jean Stiller, Anne Martin, and the Health Accounts Team. 2000. Health spending in 1998: Signals of change. Health Affairs, 19: 124132.

Lynn, Laurence Jr., Heinrich, Carolyn, and Carolyn Hill. 2000. Studying Governance and Public Management: Challenges and Prospects. Journal of Public Administration Research and Theory, 10 (2) 233-261.

Meier, Kenneth J. and Laurence J. O'Toole, Jr. 2003. Public Management and Educational Performance: The Impact of Managerial Networking. Public Administration Review, 63(6): 689-699. . 2013a. Subjective organizational performance and measurement error: Common source bias and spurious relationships. Journal of Public Administration Research and Theory, 23(2): 429-456.

- 2013b. I think (I am doing well), therefore I am: Assessing the validity of Administrators' Selfassessments of performance. Journal of Public Administration Research and Theory, 23(2): 429-456.

Moore, Mark H. 1995. Creating public value: Strategic management in government. Cambridge, MA: Harvard University Press.

Moynihan, Donald. 2008. The dynamics of performance management. Washington, DC: Georgetown University Press.

Moynihan, Donald and Sanjay Pandey. 2005. Testing how management matters in an era of government by performance management. Journal of Public Administration Research and Theory, 15(3): 421-439.

Nicholson-Crotty, Sean and Laurence J. O'Toole, Jr. 2004. Public management and organizational performance: The case of law enforcement agencies. Journal of Public Administration Research and Theory, 14 (1): 118.

O’Mahony, Mary and Philip Stevens. 2006. International comparisons of output and productivity in public service provision: A review. In Public Service Performance: Perspectives on Measurement and Management, ed. George A. Boyne, Kenneth J. Meier, Laurence J. O’Toole, Jr., and Richard M. Walker, 233-253. Cambridge, MA: Cambridge University Press.

O'Neill, Ciaran, Charlene Harrington, Martin Kitchener, and Debra Saliba. 2003. Quality of care in nursing homes: An analysis of relationships among profit, quality, and ownership. Medical Care, 41(12): 1315-1322.

Oshagbemi, Titus. 2004. Age Influences on the Leadership Styles and Behavior of Managers. Employee Relations, $26(1 / 2), 14-29$.

Oshagbemi, Titus and Roger Gill. 2003. Gender differences and similarities in the leadership styles and behavior of UK managers. Women in Management Review, 18 (5/6): 288-298.

Ortt, J.R., and van der Duin, P.A. 2008. The evolution of innovation management towards contextual innovation. European Journal of Innovation Management, 11 (4), 522-538.

O'Toole, Laurence J., Jr. 1997. Implementing public innovations in network settings. Administration and Society, 29 (2): 115-138.

O'Toole, Laurence J., Jr., and Kenneth J. Meier. 2011. Public Management: Organizations, Governance, and Performance. Cambridge: Cambridge University Press.

Palmer, Jennifer, Mark Meterko, Shibei Zhao, Dan Berlowitz, Esther Mobley, and Christine Hartmann. 2013. Nursing home employee perceptions of culture change. Research in Gerontological Nursing, 6(3): 152160.

Pandey, Sanjay and Donald Moynihan. 2006. Bureaucratic red tape and organizational performance: testing the moderating role of culture and political support. In Public Service Performance: Perspectives on Measurement and Management, ed. George A. Boyne, Kenneth J. Meier, Laurence J. O'Toole, Jr., and Richard M. Walker, 130-151. Cambridge, MA: Cambridge University Press.

Radin, Beryl. 2006. Challenging the performance movement: Accountability, complexity, and democratic values. Washington, DC: Georgetown University Press.

Raelin, Joseph A. 2012. Dialogue and deliberation as expressions of democratic leadership in participatory organizational change. Journal of Organizational Change Management, 25 (1): 7-23.

Rainey, Hal G. and Paula Steinbauer. 1999. Galloping elephants: Developing elements of a theory of effective government organizations. Journal of Public Administration Research and Theory, 9(1), 1-32. 
Rainey, Hal G., Backoff Robert, and Charles Levine. 1976. Comparing public and private organizations. Public Administration Review, 36 (2): 236-37.

Rainey, Hal G. and Young Han Chun. 2005. Public and private management compared. In The Oxford handbook of public management, ed, Laurence Lynn, Jr., Christopher Pollitt, and Ewan Ferlie. Oxford: Oxford University Press.

Rogers, E.M. (2003). Diffusion of innovations (5th ed.). New York: Free Press.

Rogers, E. M. (2004). A prospective and retrospective look at the diffusion model. Journal of Health Communication, 9 (Supplement 1), 13-19.

Rondeau, Kent V. and Terry H. Wagar. 2001. Impact of human resource management practices on nursing home performance. Health Services Management Research, 14 (3): 192-202.

Salamon, Lester M. 1987. Partners in public service: The scope and theory of government-nonprofit relations. In The nonprofit sector: A research handbook, ed. W.W. Powell, 99-117. New Haven, CT: Yale University Press.

2002. The resilient sector: The state of nonprofit America. In The state of nonprofit America, ed. Salamon, Lester, 3-64. Brookings Institution Press: Washington, DC.

Santerre, Rexford E. and Vernon, John A. 2005. Testing for ownership mix efficiency: The case of the nursing home industry. Cambridge: National Bureau of Economic Research. Working paper 11115. http://www.nber.org/papers/w11115.

Scanlon, William J. 1980. A theory of the nursing home market. Inquiry 17(1): 25-41.

Selden, Sally C., and Jessica E. Sowa. 2004. Testing a multi-dimensional model of organizational performance: Prospects and problems. The Journal of Public Administration Research and Theory, 14 (3): 395-416.

Shingler John, Mollie E. Van Loon, Theodore R. Alter and Jeffrey C. Bridger. 2008. The importance of subjective data for public agency performance evaluation. Public Administration Review, 68 (6): 1101-1111.

Smith, Peter C. 2006. Quantitative approaches towards assessing organizational performance. In Public Service Performance: Perspectives on Measurement and Management, ed. George A. Boyne, et al. 75-91. Cambridge, MA: Cambridge University Press.

Steinberg, Richard. 2006. Economic theories of nonprofit organizations. In The nonprofit sector: A research handbook, ed. W. Powell and R. Steinberg, 117-139. New Haven, CT and London: Yale University Press.

Stewart, Jenny and Paul Kringas. 2003. Change management - strategy and values in six agencies from the Australian public service. Public Administration Review, 63 (6), 675-688.

The Lewin Group. 2002. Payer-specific financial analysis of nursing facilities. Falls Church, VA: Author.

Thomas, Katie. 2014. Medicare start ratings allow nursing homes to game the system. The New York Times, August 24 2014. Retrieved 9/12/2014 from the web site: http://nyti.ms/1mFUPhZ

Thomas, Day. (n.d.). Guide to Long Term Care Planning. About Nursing Homes. National Care Planning Council. Retrieved 10/21/2014 from the web site: http://www.longtermcarelink.net/eldercare/nursing home.htm

Thomson, Ann Marie, and James L. Perry. 2006. Collaboration process: Inside the black box. Public Administration Review 66 (December Special Issue): 20-32.

Tomlinson, Julie. 2012. Exploration of transformational and distributed leadership. Nursing Management. 19(4), 30-34.

Townsley, Gail, Susan Bech, and Ginette Pepper. 2013. Predictors of quality in rural nursing homes using standard and novel methods. Research in Gerontological Nursing, 6 (2): 116-126.

Van Eijk, Carola and Trudi Steen. 2015. "Why Is This Citizen Entering my Domain?" Paper presented at the International Institute of Administrative Science Study Group, Nijmegen, the Netherlands, June 8-9.

Van Ryzin, Gregg G., Stephen Immerwahr and Stan Altman. 2008. Measuring street cleanliness: A comparison of New York City's scorecard and results from a citizen survey. Public Administration Review, 68(2): 295303.

Weiss, Michael J., Howard S. Bloom, and Thomas Brock. 2014. A conceptual framework for studying the sources of variation in program effects. Journal of Policy Analysis and Management,

Yan, Aimin and Meryl R. Louis. 1999. The migration of organizational functions to the work unit level: Buffering, spanning, and bringing up boundaries. Human Relations, 52 (1): 25- 47. 


\section{Appendix A.}

Comparison of All Operating US Nursing Homes to Our Sample.

\begin{tabular}{|l|c|c|c|c|c|c|c|c|}
\hline & \multicolumn{3}{c}{ Population } & $(\mathbf{2 0 1 3 - 2 0 1 2}$ wave) & \multicolumn{3}{c}{ Sample (2013-2012 wave) } \\
\hline Variables & For-profit & Nonprofit & Public & & For-profit & Nonprofit & Public \\
\hline Percent residents on Medicaid (means) & 63.2 & 49.0 & 62.1 & & 62.4 & 50.3 & 62.0 \\
\hline Number of certified beds (means) & 109.6 & 94.3 & 115.0 & & 110.5 & 94.7 & 105.4 \\
\hline Number of residents (means) & 89.2 & 81.2 & 95.0 & & 91.5 & 83.2 & 90.0 \\
\hline Total nurse hours per resident per day (means) & 3.9 & 4.5 & 4.5 & & 3.9 & 4.4 & 4.5 \\
\hline Hospital affiliation (percent "affiliated") & 1.1 & 14.5 & 26.2 & & 0.9 & 12.4 & 19.6 \\
\hline Number of health deficiencies (means) & 7.5 & 5.4 & 6.4 & & 6.7 & 5.0 & 6.0 \\
\hline Overall 5-star rating (means) & 3.2 & 3.8 & 3.6 & & 3.2 & 4.0 & 3.7 \\
\hline
\end{tabular}

